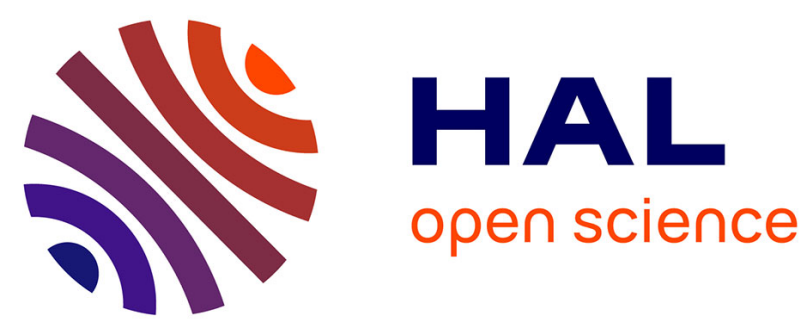

\title{
HIGH EXCITATION ENERGY STRUCTURES IN HEAVY ION COLLISIONS ON A208Pb TARGET
}

\author{
Y. Blumenfeld, Ph. Chomaz, N. Frascaria, J. Garron, J. Jacmart, J.
}

Roynette, W. Bohne, W. von Oertzen, M. Buenerd, A. Gamp, et al.

\section{- To cite this version:}

Y. Blumenfeld, Ph. Chomaz, N. Frascaria, J. Garron, J. Jacmart, et al.. HIGH EXCITATION ENERGY STRUCTURES IN HEAVY ION COLLISIONS ON A208Pb TARGET. International Symposium on Highly Excited States and Nuclear Structure Hesans 83, 1983, Orsay, France. pp.C4-201-C4205, 10.1051/jphyscol:1984415 . jpa-00224080

\section{HAL Id: jpa-00224080 https://hal.science/jpa-00224080}

Submitted on 1 Jan 1984

HAL is a multi-disciplinary open access archive for the deposit and dissemination of scientific research documents, whether they are published or not. The documents may come from teaching and research institutions in France or abroad, or from public or private research centers.
L'archive ouverte pluridisciplinaire HAL, est destinée au dépôt et à la diffusion de documents scientifiques de niveau recherche, publiés ou non, émanant des établissements d'enseignement et de recherche français ou étrangers, des laboratoires publics ou privés. 

TARGET

Y. Blumenfeld, Ph. Chomaz, N. Frascaria, J.P. Garron, J.C. Jacmart, J.C. Roynette, W. Bohne*, W. Von Oertzen ${ }^{\star}$, M. Buenerd丸, A. Gamp ${ }^{\star}$, D. Lebrun ${ }^{\star}$ and $\mathrm{Ph}$. Martin $\star \star$

Institut de Physique Nucléaire, Orsay, France *Hahn Meitner Institut, Berlin, F.R.G.

* Institut des Sciences Nucléaires, Grenoble, France

Résumé : Des stxuctures ont été observées dans les spectres en énergie des fragments issus des réactions $36_{\mathrm{Ar}}+208 \mathrm{~Pb}$ à $11 \mathrm{MeV} / \mathrm{n}$ et $20_{\mathrm{Ne}}+208 \mathrm{~Pb}$ à $30 \mathrm{MeV} / \mathrm{n}$ jusqu'à une énergie d'excitation d'environ $130 \mathrm{MeV}$. L'identification complète en masse et en charge, a été obtenue à 1'aide d'un système de temps de vol associé à un télescope $\Delta \mathbf{E} . \mathbf{E}$. Il est montré que ces structures sont dues à l'excitation du noyau cible.

Abstract: Energy spectra of fragments from the $36 \mathrm{Ar}+208_{\mathrm{Pb}}$ reaction at $11 \mathrm{MeV} / \mathrm{n}$ and $20 \mathrm{Ne}+208 \mathrm{pb}$ reaction at $30 \mathrm{MeV} / \mathrm{n}$ were measured using a time of flight spectrometer. Structures ranging up to $130 \mathrm{MeV}$ excitation energy are observed in the inelastic spectra. These structures are shown to be due to an excitation of the $208 \mathrm{~Pb}$ target nucleus.

$I-$ Introduction

The gross features of the energy spectra of ejectiles from heavy ion collisions at low bombarding energies ( $\leqq 10 \mathrm{MeV} / \mathrm{n}$ ) can be interpreted in terms of two main reaction mechanisms : peripherical collisions (inelastic or transfer reactions) and more central collisions caracterised by a complete energy relaxation (deep inelastic reactions). A detailed study of these energy spectra in several symmetric or nearly symmetric heavy ion reactions revealed the additional presence of broad structures ranging up to an excitation energy of approximately $130 \mathrm{MeV} / 1-3 /$. More detailed information on these bumps was subsquently obtained by the study of the $40 \mathrm{Ca}+40 \mathrm{Ca}$ col1ision at three different incident energies $4 \mathrm{MeV} / \mathrm{n} / 4 /, 7.5 \mathrm{MeV} / \mathrm{n} / 1 /$ and $10 \mathrm{MeV} / \mathrm{n} / 5 /$. The main features of the high excitation energy (H.E.E.) structures can be summarized as follow : i) They are only observed in the inelastic and few nucleon transfer channels. ii) Their excitation energies are independent of angle. iii) Within the allowed excitation energy ranges, their positions are independent of beam energy. iiii) The structures are observed more clearly at higher excitation energy. iiiii) Their widths increase with increasing excitation energy $E_{x}[\Gamma \sim 5 \mathrm{MeV}$ for $E_{\mathrm{X}} \sim 25 \mathrm{MeV}$ and $\Gamma \backsim 25 \mathrm{MeV}$ for $\left.\mathrm{E}_{\mathrm{Xx}} \sim 100 \mathrm{MeV}\right]$. Several interpretations have been given /5/ up to now but have failed in reproducing all the features of the data. A possible interpretation consistent with these observations is the excitation of high energy collective modes such as giant resonances.

Until recently these studies were limited to symmetric systems. Thus a certain number of open questions remain, the first of which being whether or not such structures are also observed in very asymmetric collisions. Furthermore, in such reactions where two heavy nuclei collide many degrees of freedom are involved and it is legitimate to ask if the observed bumps are due to an excitation of the target nucleus, the projectile nucleus, a mutual excitation or even to the existence of a short lived composite system.

To check the above mentionned interpretation and to answer the preceding questions, two new experiments have been performed by bombarding a $208 \mathrm{~Pb}$ target with 
$11 \mathrm{MeV} / \mathrm{n} 36 \mathrm{Ar}$ and $30 \mathrm{MeV} / \mathrm{n} 20 \mathrm{Ne}$ beams. The experimental procedures will be described below and subsequently the results will be presented and discussed.

\section{II - Experimental set up}

\section{1 36 Ar $+208 \mathrm{pb}$ expeximent}

The $392 \mathrm{MeV} 36 \mathrm{Ar}$ beam from the VICKSI accelerator of Berlin was used to bombard a $500 \mu \mathrm{g} / \mathrm{cm}^{2}$ isotopically pure $\mathrm{Pb}$ target deposited on a thin carbon backing. In order to obtain an unambiguous mass and charge identification of the heavy ejectiles together with a goodenergy resolution a time of flight set up was used. The start signal was obtained by accelerating the electrons emitted by a $40 \mu \mathrm{g} / \mathrm{cm}^{2} \mathrm{car}-$ bon foil set at $45^{\circ}$ to the incident particles onto two microchannel plates. The accelerating system used a set of 5 electrodes instead of the usual grid in order to avoid creating parasite structures in the energy spectra of the detected fragments. The stop signal was given by two solid state $E$ detectors having an angular separation of $1^{\circ}$ associated with a $\Delta E$ gaz ionisation chamber for charge identification. The flight path was $160 \mathrm{~cm}$ long and the time resolution $\sim 130$ ps yielding a mass resolution $\Delta \mathrm{m} \sim 1 \%$. The overall energy resolution was $\Delta \mathrm{E} \sim 2.5 \mathrm{MeV}$. The measured angles were $\theta_{1 \mathrm{ab}}=15,20,25$ and $30^{\circ}$, the calculated grazing angle for the reaction being $\theta_{\text {graz }} \sim 28^{\circ}$.

\section{II.2 $20 \mathrm{Ne}+208 \mathrm{~Pb}$ experiment}

In this case, a $1 \mathrm{mg} / \mathrm{cm}^{2} \quad{ }^{208} \mathrm{~Pb}$ target was bombarded with the $600 \mathrm{MeV}$ $20 \mathrm{Ne}$ beam of the SARA facility in Grenoble. The experimental set up was similar to the one described above, the ionisation chamber being replaced by two $\Delta E$ silicon surface barrier detectors from which the stop signals were derived. Because of the lighter projectile and higher incident energy a conventionnal E. $\Delta E$ solid state telescope also yielded an excellent mass identification in addition to the usual charge separation. The measurement was performed at only one angle $\Theta_{1 a b}=10^{\circ}$, the grazing angle for the reaction. The total energy resolution was $\triangle \mathrm{E} \& 3.5 \mathrm{MeV}$.

\section{III - Results and discussion}

This paper will be focused on the inelastic spectra measured in both studied reactions. The transfer channel spectra, where structures are also observed will be presented elsewhere /6/. Because of the very high elastic peaks, all the inelastic spectra will be presented using a logarithmic scale. The indicated excitation energies are calculated assuming two body reactions.

\section{1 Pick_up-break_up_contribution}

It is well known that the contribution to the spectra of the so-called pick up-break up mechanism can be important. This process consists of particle trans fers from the target to the projectile nucleus followed by the subsequent de-excitation of this quasi projectile by emission of nucleons of the same type as the transfered nucleons (for example $36 \mathrm{Ar}+208 \mathrm{~Pb} \rightarrow 37 \mathrm{Ar}+207 \mathrm{~Pb} \rightarrow 36 \mathrm{Ar}+207 \mathrm{~Pb}+\mathrm{n}$ ). The dominant contribution is due to the one nucleon transfer. It can generate bumps in the energy spectrum of the residual nucleus centered at an apparent excitation energy $E^{*}$ which can be calculated by

$$
E^{*} \approx \frac{E_{1 a b}}{A_{P}+1}-\frac{A_{P}\left(A_{T}-1\right)}{A_{T}} Q_{T}+E_{I p}\left(\frac{A_{T}-1}{A_{T}}+\frac{A_{T}+A_{P}}{A_{T}(A p+1)}\right)
$$

where $A_{P}$ and $A_{T}$ are respectively the projectile and target mass numbers, Elab the incident laboratory energy, $E_{1 p}$ the average kinetic energy of the emitted nucleon and $Q$ the $Q$ value for the pick up-break up reaction.

\begin{tabular}{|l|c|c|}
\hline Transfer Réaction & ${ }^{36} \mathrm{Ar}^{208}{ }_{\mathrm{Pb}, \mathrm{E}_{\mathrm{lab}}=400 \mathrm{MeV}}$ & ${ }_{\mathrm{Ne}}{ }^{208} \mathrm{~Pb}, \mathrm{E}_{1 \mathrm{ab}}=600 \mathrm{MeV}$ \\
\hline Neutron transfer & $\mathrm{E}^{*} \sim 23 \mathrm{MeV}$ & $\mathrm{E}^{*} \sim 39^{\circ} \mathrm{MeV}$ \\
\hline Proton transfer & $\mathrm{E}^{*} \sim 26 \mathrm{MeV}$ & $\mathrm{E}^{*} \sim 41 \mathrm{MeV}$ \\
\hline
\end{tabular}


This determination is straight forward but a correct calculation of the width and cross sections of these contributions is much more delicate /3/. Thus, in the following paragraphs we will not include in our discussion the region of the inelastic spectra where this contribution is present.

\section{2 Experimental rese}

$$
\text { III } 2 \mathrm{a} \cdot{ }^{36} \mathrm{Ar}+{ }^{208} \mathrm{~Pb} \text { experiment }
$$

Figure 1 presents the low excitation energy part ( $\mathrm{Ex} \leqq 40 \mathrm{MeV}$ ) of the inelastic spectra from the $\mathrm{Ar}+\mathrm{Pb}$ reaction at the four measured angles. Bumps superimposed on the high tail of the elastic peak, clearly show up at all angles at excitation energies $\mathrm{Ex}=11.5,13.5,17.5,21.5,25.5$ and $35 \mathrm{MeV} \pm 1 \mathrm{MeV}$. The position of the first one is in good agreement with the well known giant quadrupole resonance (G.Q.R.) in ${ }^{208} \mathrm{~Pb}$. The three following bumps have already been observed in other light ion and light heavy ion experiments / 7-8/. The peak at $13.5 \mathrm{MeV}$ was assumed to arise from both the giant monopole (G.M.R.) and the giant dipole (G.D.R.) resonances $/ 8 /$ while the peak at $17.5 \mathrm{MeV}$ was related to the high excitation octupole resonance (H.E.O.R.) /7/. The $21.5 \mathrm{MeV}$ bump was found to be a mixture of the giant isoscalar dipole and high multipolarity giant resonances $/ 7 /$.

Since the structures at much higher excitation energy are expected to be very wide a compression of the spectra (2 MeV/channel instead of $0.5 \mathrm{MeV} / \mathrm{channel}$ ) permits their clear observation up to excitation energies above $100 \mathrm{MeV}$ (fig. 2). The estimated error on the positions of these high excitation energy structures is about $\pm 3 \mathrm{MeV}$. The width of the observed structures are seen to increase with increasing excitation energy.

Angular distributions for four of the observed structures are presented on fig. 3. They result from the integration of the bumps after subtraction of an estimated background. The error bars include both the statiscal exror and an estimated error on the background. While at $\mathrm{E}_{\mathbf{X}}=25 \mathrm{MeV}$ the background is very important due to the tail of the elastic peak at the higher excitation energies $\left(E_{\mathrm{x}}=96\right.$ and $138 \mathrm{MeV})$ it has almost entirely dissapeared leaving only the statistical errors. The angular distribution of the $\mathrm{E}_{\mathrm{X}}=25 \mathrm{MeV}$ structure shows a strong maximum at the grazing angle $\left(\Theta_{\mathrm{graz}}=28^{\circ}\right)$. At $\mathrm{E}_{\mathrm{X}}=52 \mathrm{MeV}$ the maximum is less pronounced and has moved towards a smaller angle while the structures at highest excitation energy have a monotically decreasing angular distribution and their cross section vanishes almost completely at $\Theta_{1 a b}=30^{\circ}$.

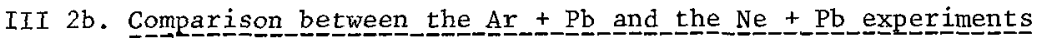

Fig. 5 displays the inelastic spectra of $36 \mathrm{Ar}$ and $20 \mathrm{Ne}$ measured respectively at $\theta_{1 \mathrm{ab}}=20^{\circ}$ and $10^{\circ}$. The general trends of these two spectra are strikingly similar, except in the region of $\sim 35 \mathrm{MeV}$ excitation where the contribution of the pick up-break up process is expected in the $20_{\mathrm{Ne}}+208 \mathrm{~Pb}$ experiment. In addition of the low lying giant resonances at $11.5,17.5,21 \mathrm{MeV}$ which are clearly observed in both reactions (see fig. 2), at excitation energies above $40 \mathrm{MeV}$ the H.E.E. structures are present at the same excitation energies in both spectra up to approximately $100 \mathrm{MeV}$ excitation energy ( $\mathrm{Ex}=44,52,61,73 \pm 3 \mathrm{MeV})$. This independence of the position of the structures on bombarding energy and projectile mass unambigously demonstrates that an excitation of the $208 \mathrm{~Pb}$ target is responsible for these structures.

Another remarkable feature given by the comparison of the two inelastic spectra for angles close to the grazing angle for each reaction is that both the ratio between the inelastic and elastic cross sections and the absolute inelastic cross section are much more favourable in the case of the $30 \mathrm{MeV} / \mathrm{A} 20_{\mathrm{Ne}}$ projectile. The absolute double differential cross section $\mathrm{d}^{2} \sigma / \mathrm{d} \Omega \mathrm{dE}$ is approximately 20 times greater for the higher energy projectile in the region of interest. These results are encouraging for future high energy studies to be performed at the GANIL facility. 


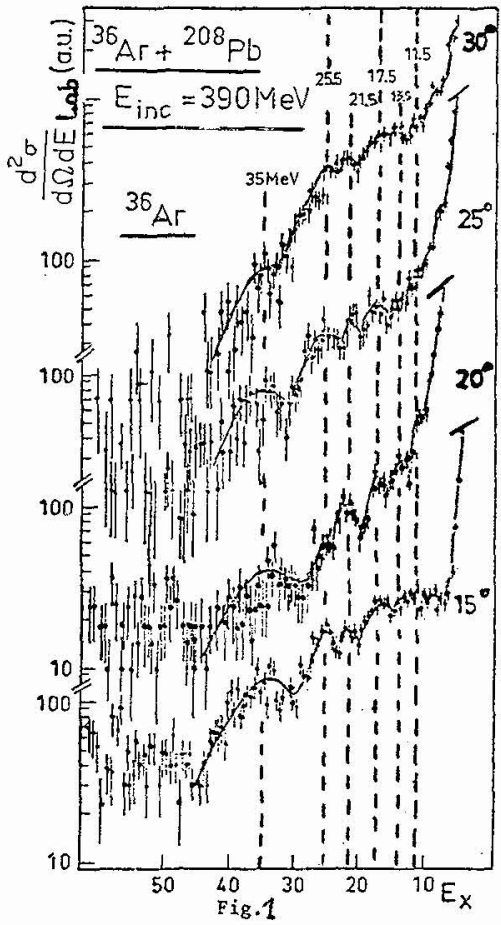

Fig.1,2 - Energy spectra at different angles of inelastically scattered $36 \mathrm{Ar}$ from the $36 \mathrm{Ar}+208_{\mathrm{Pb}}$ reaction at $\mathrm{E}_{1 \mathrm{ab}}=11 \mathrm{MeV} / \mathrm{n}$ (see text).

Fig.3 - Angular distribution for 4 of the observed structures (see text)

Fig.4 - Comparison of the inelastic channels for both studied reactions.

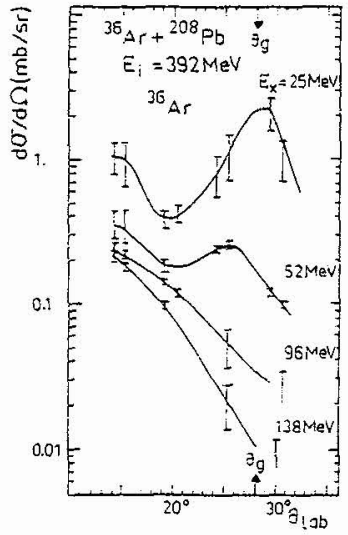

Fig. 3
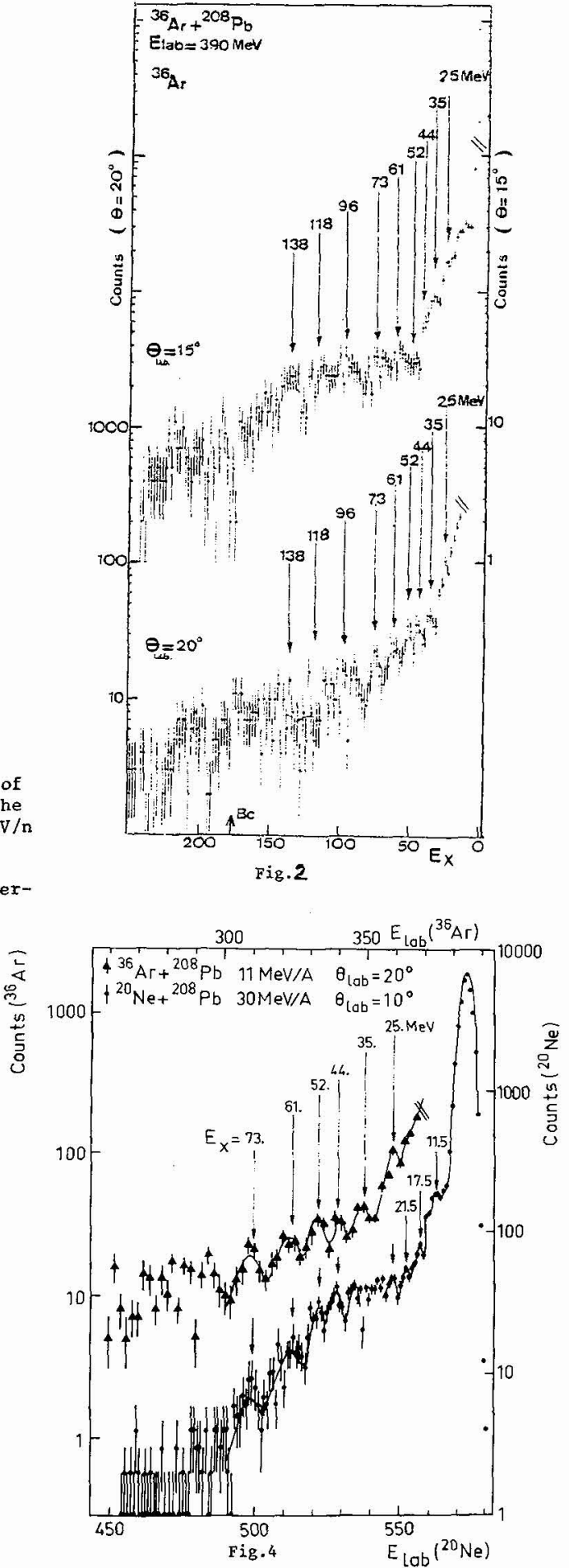
IV - Sumnary and conclusion

The inelastic spectra produced in two very asymmetric heavy ion collisions $36_{\mathrm{Ar}}+208 \mathrm{pb}$ and $20 \mathrm{Ne}+208 \mathrm{~Pb}$ have been measured at bombarding energies of respectively $11 \mathrm{MeV} / \mathrm{n}$ and $30 \mathrm{MeV} / \mathrm{n}$. The giant quadrupole resonance is clearly excited in these reactions. At high excitation energies, structures of the same type as those previously observed in symmetric systems are strongly populated in these asymmetric collisions but are more numerous and narrower than the ones observed in the $40 \mathrm{Ca}+40 \mathrm{Ca}$ experiment. Furthermore, these structures lie at the same excitation energies for the two studied reactions. It is now clearly established that their positions are independent of angle, incident energy and the nature of the projectile. This clearly proves that they are due to an excitation of the target nucleus. In the light of these new results the hypothesis of an excitation of collective modes such as giant resonances in these heavy ion reactions is strengthened.

\section{REFERENCES}

11/ Frascaria N., Stéphan C., Colombani P., Garron J.P., Jacmart J.C., Riou M. and Tassan-Got L., Phys. Rev. Lett. 39 (1977) 918.

/2/ Mignerey A.C., Wolf K.L., Breuer H., Glagola B.G., Viola V.E., Birkelund J.R., Hilscher D., Huizenga J.R., Schröder W.U. and Wilcke W.W., Proc. Int. Conf. on Nucl. Phys., Berkeley (1980) 611.

13/ Pontopiddan S., Christensen P.R., Hansen Ole, Videback F., Britt H.C., Erkkela B.H., Gavron A., Patin Y., Stokes R.H., Webb M.P., Fergusen R.L., Plasil F., Young G.R., To be published in Phys. Rev. C.

14/ Blumenfeld Y., Frascaria N., Garron J.P., Jacmart J.C., Roynette J.C., Ardouin D. and Lattuada M., Phys. Rev. C 25 (1982) 2116.

15/ Frascaria N., Colombani P., Gamp A., Garron J.P., Riou M., Roynette J.C., Stéphan C., Ameaume A., Bizard C., Laville J.L. and Louvel M., Z. Phys. A 294 (1980) 167 and Frascaria N., Proc. of Int. Conf. Irieste (Ita1y) Nucl. Phys. (1982) 617.

16/ Frascaria N.,, Chomaz P., Blumenfeld Y., Garron J.P., Jacmart J.C., Pollacco E., Roynette J.C., Bohne W., Gamp A., Von Dertzen W., Proc. Int. Conf. on Nucl. Phys. Florence (1983) 516 and to be published.

/7/ Morsch H.P., Sukösd C., Regge M., Turek P., Machner H. and Mayer-Böricke C., Phys. Rev. C 22 (1980) 489.

Djalali C. Thèse 3ème cycle Orsay (1981) IPNO - T - 81-02

18/ Bertrand F., This Conference 